8 Alffenaar JW, van Altena R, Harmelink IM, et al. Comparison of the pharmacokinetics of two dosage regimens of linezolid in multidrug-resistant and extensively drug-resistant tuberculosis patients. Clin Pharmacokinet 2010; 49: 559-565.

9 Koh WJ, Kang YR, Jeon K, et al. Daily $300 \mathrm{mg}$ dose of linezolid for multidrug-resistant and extensively drug-resistant tuberculosis: updated analysis of 51 patients. J Antimicrob Chemother 2012; 67: $1503-1507$.

10 Srivastava S, Peloquin CA, Sotgiu G, et al. Therapeutic drug management: is it the future of multidrug-resistant tuberculosis treatment? Eur Respir J 2013; 42: 1449-1453.

11 Bolhuis MS, van Altena R, van Soolingen D, et al. Clarithromycin increases linezolid exposure in multidrug-resistant tuberculosis patients. Eur Respir J 2013; 42: 1614-1621.

\title{
Key role of tuberculosis services funding mechanisms in tuberculosis control and elimination
}

To the Editor:

We read with interest the systematic review by TANIMURA et al. [1], looking at the existing studies focusing on costs and income loss incurred by tuberculosis (TB) patients and their families in low- or middle-income countries, and the related editorial [2]. The TB-related "catastrophic expenditures" are one of the main reasons that prevent patients completing their treatment, thus making TB control challenging. Based on the new post-2015 strategy of the World Health Organization (WHO), the authors strongly advocate for universal health coverage and social protection.

TB-related direct and indirect costs and cost-effectiveness of TB interventions are crucial, and the European Respiratory Journal has published several important contributions including the cost of an individual treatment (which is enormous in case of extensively drug-resistance (XDR)-TB) [3] and the corresponding costs projected for the whole of Europe [4]. Furthermore, the important study by FLoyd et al. [5] demonstrated the cost-effectiveness of managing multidrug-resistant (MDR)-TB cases in Eastern Europe.

The WHO Regional Office for Europe developed a 5 year plan (2011-2016) to prevent and combat MDR-/XDR-TB in the WHO European region with a conservative estimated budget of US $\$ 5.2$ billion. The costing scenario was based on the average cost of 3 months inpatient care for MDR-TB patients. Under this scenario, $38 \%$ of the budget would be for inpatient care. If the average length of hospital stay is 8 months as it is in many countries in the region (a figure driven by admission habits in Eastern Europe, as the duration of hospital stay in Western Europe is generally much lower), the percentage for inpatient care would be above $70 \%$ of the overall budget. Analysis of various costing scenarios showed that, with variations in inpatient care, the budget for implementation of the plan could range from US $\$ 3.7$ billion to US $\$ 9.8$ billion [6]. Implementation of the plan leads to average direct savings of US $\$ 7$ billion.

Last but not least, a recent report on the XDR-TB outbreak in Milan [7], although not formally evaluated with economic analysis, underlined the large number of activities (which represent large costs) necessary for managing micro-epidemics in low TB incidence countries and the importance of preventing TB as far as possible.

The concepts of TB elimination (i.e. $<1$ case per million population) and the role of TB prevention are clearly embedded in the new WHO post-2015 Global Strategy [8-10]. If TB elimination is to be reached, we believe that other economic topics need to be discussed in detail. Among them, incorrectly conceptualised mechanisms of TB service funding might render the adoption of new cost-saving strategies impossible.

In a recent study [11], the authors presented the case of Armenia as an example of what happens in all countries belonging to the former Soviet Union. In these settings (relevant TB incidence and very high MDR-TB prevalence [5]), the organisation of TB services is based on a vertical and specialised system with extensive hospitalisation, which is expensive and, in absence of adequate infection control practices, favours nosocomial MDR-TB transmission. The expenditures of TB services, for example staff salaries, inpatient and ambulatory care costs, are covered by the government. 


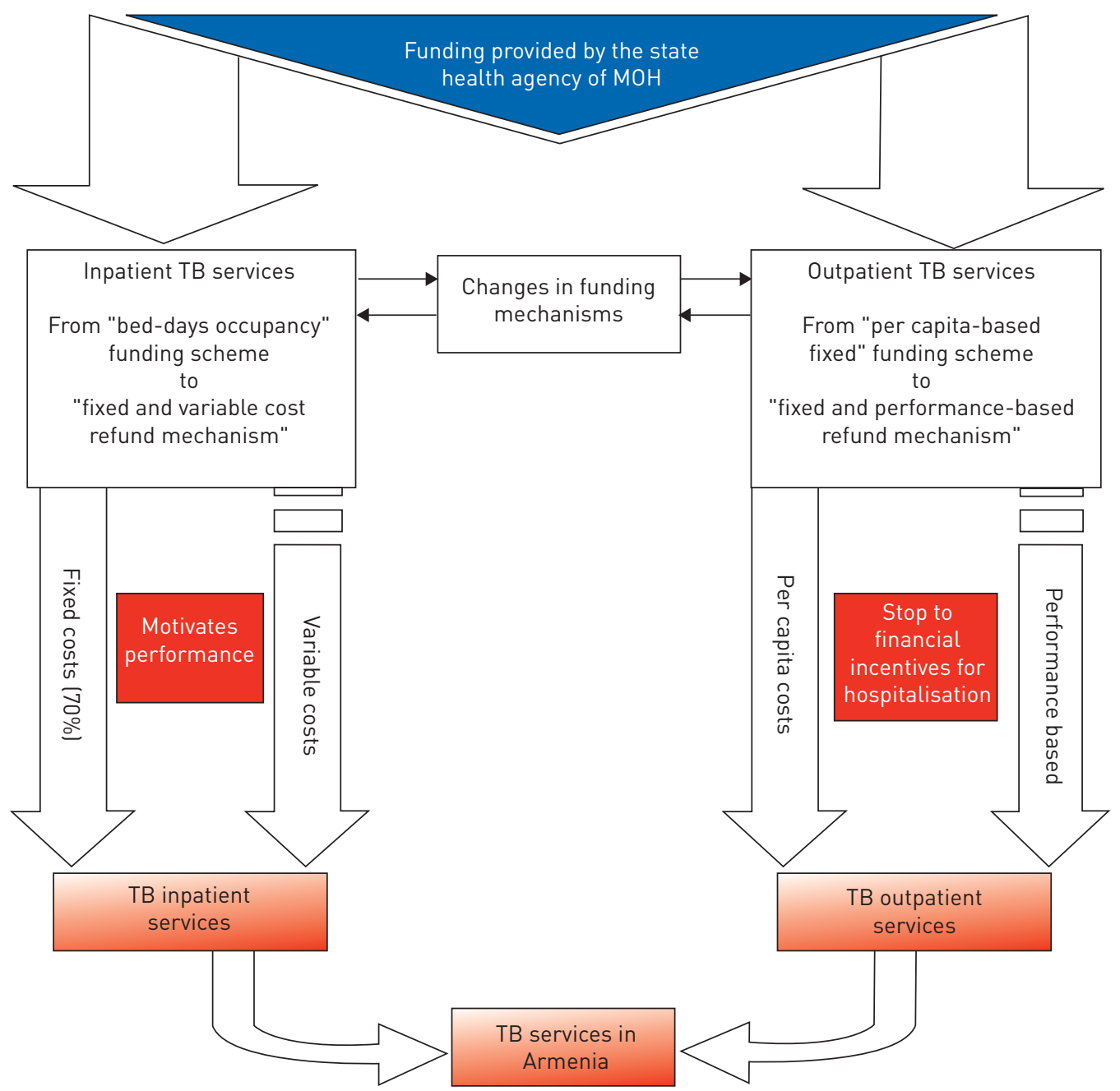

FIGURE 1 Summary of the changes occurring in Armenia to finance "inpatient" and "outpatient" services. In Armenia $95 \%$ of patients were admitted for $>55$ days to receive the intensive phase of treatment (a maximum of 60 bed-days was allowed for refund). Before the Governmental decision (in December 2013), the Governmental Protocol N21 (May 29, 2013) had been issued, representing the start of the financial reform of tuberculosis (TB) hospital care. It specified that financing would switch from bed occupancy per day to refund of fixed and variable costs in all TB inpatient health services, including hospitals and dispensaries (where $90 \%$ of admissions occur). In this scenario the number of TB beds in dispensaries will be reduced by $30 \%$ by 2015 , while an additional $12 \%$ decrease in the total number of hospital beds had been planned by closing four out of the seven regional TB inpatient departments. This re-organisation aims to achieve financial savings, improvement in both TB specialists' and patients' satisfaction, and produce a gradual shift of experienced TB doctors from hospitals to outpatient services (which currently face a lack of staff). Finally, the reform is expected to increase both TB detection and treatment success in Armenia. MOH: Ministry of Health.

In Armenia, up until 2014, the funding scheme for TB care was based on bed occupancy per day [11]. In 2012, the cost of 1 bed-day was 8900 Armenian Drams (AMD) (approximately $€ 20$ ), while the cost of one TB outpatient visit was about 5.6 times cheaper $(\sim 1600$ AMD or $€ 3)$ [11]. The funding for outpatient activities was fixed (based on the facility catchment population and not on performance) and TB healthcare staff would not receive incentives to increase the daily number of medical visits.

TB physicians (receiving a fixed salary) are not encouraged to manage TB cases in an outpatient setting and may choose to refer them for admission. As a consequence, $80 \%$ of the TB case-load is absorbed by inpatient care versus $20 \%$ managed by the ambulatory system. This mechanism creates an unfair competition for resources between the "old" hospital-centred and the "new" patient-centred model, which is strongly recommended by WHO in order to reduce TB-related costs and the risk of nosocomial TB transmission. The Armenian Ministry of Health has been considering revision of the funding mechanism for TB services, following coordinated activity conducted by several organisations (Armenia National TB programme; WHO Regional Office for Europe; WHO Collaborating Centre for Tuberculosis and Lung 
Diseases, Tradate, Italy; and USAID/Abt Health System Strengthening in Armenia Project) to discuss the "pros" and "cons" of different schemes.

The discussion was fruitful and the Armenian Ministry of Health decided to start modifying the "per-bed occupation" funding scheme towards a modern outpatient, performance-based scheme, which allows the money saved to be reinvested into an outpatient oriented TB programme (Governmental decision number 1515N, December 26, 2013) (fig. 1).

While strongly supporting any approach reducing the "catastrophic expenditures" for TB cases, we think that a co-ordinated effort involving the WHO, partners, scientific societies and governments is necessary to discuss the best models to finance TB services in order to ensure quality patient care and a sound implementation of new cost-effective policies.

(7) @ERSpublications

Co-ordination is crucial to find the best way to finance TB services to ensure quality care and cost-effectiveness http://ow.ly/AkdQL

Karapet Davtyan ${ }^{1,6}$, Armen Hayrapetyan ${ }^{1,6}$, Masoud Dara ${ }^{2}$, Laura Gillini ${ }^{3}$, Hayk Davtyan ${ }^{1}$, Rosella Centis ${ }^{4}$, Lia D'Ambrosio ${ }^{4}$, Giovanni Sotgiu ${ }^{5}$ and Giovanni Battista Migliori ${ }^{4}$

${ }^{1}$ National Tuberculosis Control Center, Yerevan, Armenia. ${ }^{2}$ World Health Organization, Regional Office for Europe, Copenhagen, Denmark. ${ }^{3}$ World Health Organization, Fiji Islands Office, Suva, Fiji. ${ }^{4}$ World Health Organization Collaborating Centre for Tuberculosis and Lung Diseases, Fondazione S. Maugeri, Care and Research Institute, Tradate, Italy. ${ }^{5}$ Clinical Epidemiology and Medical Statistics Unit, Dept of Biomedical Sciences, University of Sassari - Research, Medical Education and Professional Development Unit, AOU Sassari, Italy. ${ }^{6}$ Both authors contributed equally.

Correspondence: Giovanni Battista Migliori, S. Maugeri Foundation, World Health Organization Collaborating Centre for Tuberculosis and Lung Diseases, Via Roncaccio 16, Tradate, Varese, 21049, Italy.

E-mail: giovannibattista.migliori@fsm.it

Received: June 272014 | Accepted: July 222014

Conflict of interest: None declared.

\section{References}

1 Tanimura T, Jaramillo E, Weil D, et al. Financial burden for tuberculosis patients in low- and middle-income countries: a systematic review. Eur Respir J 2014; 43: 1763-1775.

2 Sotgiu G, Mauch V, Migliori GB, et al. Evidence-based, agreed-upon health priorities to remedy the tuberculosis patient's economic disaster. Eur Respir J 2014; 43: 1563-1566.

3 Diel R, Rutz S, Castell S, et al. Tuberculosis: cost of illness in Germany. Eur Respir J 2012; 40: 143-151.

4 Diel R, Vandeputte J, de Vries G, et al. Costs of tuberculosis disease in the European Union: a systematic analysis and cost calculation. Eur Respir J 2014; 43: 554-565.

5 Floyd K, Hutubessy R, Kliiman K, et al. Cost and cost-effectiveness of multidrug-resistant tuberculosis treatment in Estonia and Russia. Eur Respir J 2012; 40: 133-142.

6 Dara M, Kluge H. Roadmap to Prevent and Combat Drug-Resistant Tuberculosis. Copenhagen, WHO Regional Office for Europe, 2011.

7 Esposito S, D'Ambrosio L, Tadolini M, et al. ERS/WHO Tuberculosis Consilium assistance with extensively drug-resistant tuberculosis management in a child: case study of compassionate delamanid use. Eur Respir J 2014; 44: 811-815.

8 D'Ambrosio L, Dara M, Tadolini M, et al. Tuberculosis elimination: theory and practice in Europe. Eur Respir J 2014; 43: 1410-1420.

9 Diel R, Loddenkemper R, Zellweger J-P, et al. Old ideas to innovate tuberculosis control: preventive treatment to achieve elimination. Eur Respir J 2013; 42: 785-801.

10 Voniatis C, Migliori GB, Voniatis M, et al. Tuberculosis elimination: dream or reality? The case of Cyprus. Eur Respir J 2014; 44: 543-546.

11 Gillini L, Davtyan K, Davtyan H, et al. TB financing in East Europe promotes unnecessary hospital admissions: the case of Armenia. J Infect Dev Ctries 2013; 7: 289-292. 